\title{
Undiagnosed Hepatitis B and C Virus Infection at a Teaching Hospital in Rawalpindi
}

\author{
Muhammad Imran Khan ${ }^{1,2 *}$ (D), Fadia Kalsoom ${ }^{3}$ (D) Fakhra Batool ${ }^{4}$ (D), \\ Ahsan Kazmi ${ }^{5}$ D , Qurat-ul-ain Zahra ${ }^{1}$ D , Muhammad Bilal ${ }^{6 *}\left(\mathbb{D}\right.$, Rizwan Ali $^{1}{ }^{\mathbb{D}}$, \\ Ajkia Zaman Juthi ${ }^{1}{ }^{(D)}$ and Hafiz M.N. Iqbal' ${ }^{7}$
}

\begin{abstract}
${ }^{1}$ Hefei National Lab for Physical Sciences at the Microscale and the Centers for Biomedical Engineering, University of Science and Technology of China, Hefei, Anhui 230027, China. ${ }^{2}$ Blood Unit, Benazir Bhutto Hospital Rawalpindi 46000, Pakistan. ${ }^{3}$ Agha University Hospital Laboratory Specimen Collection Unit, Faisalabad 38000, Pakistan. ${ }^{4}$ Department of Chemistry, Government College Women University Faisalabad 38000, Pakistan. ${ }^{5}$ Department of Pathology, Al-Nafees Medical College and Hospital, Isra University Islamabad 45600, Pakistan. ${ }^{6}$ School of Life Science and Food Engineering, Huaiyin Institute of Technology, Huaian 223003, China. ${ }^{7}$ Tecnologico de Monterrey, School of Engineering and Sciences, Campus Monterre, Ave. Eugenio Garza Sada 2501, CP 64849 Monterrey, Mexico.
\end{abstract}

\begin{abstract}
Uncontrolled prevalence of hepatitis B and C virus infections is known to be a global health problem. Many cases are undiagnosed yet. So, this study focusses on the undiagnosed existence of viral infection of hepatitis B (HBV) and Hepatitis C infection (HCV) in hospitalized patients and outdoor attendees to draw a more accurate picture of the prevalence of HBV and HCV. A cross-sectional observational study at Benazir Bhutto hospital Rawalpindi Pakistan continued for seven months and included hospitalized patients and outdoor attendees. Venous blood collected from 2003 subjects and processed to investigate infection by ELISA. We observed the overall prevalence of HBV was $2.6 \%$ and HCV was $10.98 \%$. Further $4.2 \%$ was the highest infection rate of HBV in patients of Surgery and Medicine and the lowest in Orthopedics, Urology, Gynecology and Obstetrics, Pediatrics, Intensive Care Unit, Ear Throat and Nose, Eye $>\mathbf{0 . 0 0 1 \%}$. We found the highest rate of HCV infection was in Medicine $\mathbf{2 2 . 9 0 \%}$ and the lowest was in Pediatrics $>0.001 \%$. For the age, the HBV infection was found to be $4.55 \%$ the most prevalent in the age range of $61-75$ and the lowest $>0.001 \%$ in $76-90$ years. Age group $46-60$ years showed the highest $19.07 \%$ and $16-30$ years the lowest $6.44 \%$ prevalence of HCV infection. Observed HBV-positive participants were $\mathbf{6 0 . 7 8 \%}$ males and $39.22 \%$ females. While among the participants, males contributed $50.90 \%$ H C Virus infections and females contributed $49.10 \%$ infections. Although undiagnosed but prevalence of hepatitis $B$ and $C$ virus infection is very high. Therefore, some effective strategies should be implemented.
\end{abstract}

Keywords: Hepatitis B, Hepatitis C, Public Policy, Enzyme assays, Prevalence

*Correspondence: imran_almani@yahoo.com (M.I. Khan); bilaluaf@hotmail.com (M. Bilal).

(Received: April 02, 2020; accepted: April 23, 2020)

Citation: Khan MI, Kalsoom F, Batool F, et al. Undiagnosed Hepatitis B and C Virus Infection at a Teaching Hospital in Rawalpindi. J Pure Appl Microbiol. 2020;14(2):1279-1286. doi: 10.22207/JPAM.14.2.23

(C) The Author(s) 2020. Open Access. This article is distributed under the terms of the Creative Commons Attribution 4.0 International License which permits unrestricted use, sharing, distribution, and reproduction in any medium, provided you give appropriate credit to the original author(s) and the source, provide a link to the Creative Commons license, and indicate if changes were made. 


\section{INTRODUCTION}

Scientific findings are often serendipitous. Such was the case with the discovery of the Hepatitis B virus (HBV). A protein synthesized by human body that reacted with an "Australia antigen" and confirmed as the HBV surface antigen ( $\mathrm{HBsAg})^{1}$. Then, the hepatitis $\mathrm{C}$ virus (HCV) discovery was the direct result $\mathrm{HBV}$ and Hepatitis A virus (HAV) discoveries. The causative agent remained a virologic enigma until researchers sequenced its entire genome and recognized as a novel virus flavivirus later known as $\mathrm{HCV}^{2}$ and named in $1989^{3}$.

Chronic HCV (CHCV) is a common and important cause of hepatitis leading towards endstage liver disease liver cirrhosis, and cancer and Insulin resistance ${ }^{4,5}$, that is a metabolic disorder leading to the development of Diabetes mellitus ${ }^{6}$. $\mathrm{HBV}$ and HCV are reported to be one of the most common causes of Hepatocellular carcinoma (HCC). HCC contributes $90 \%$ to the third most common cause of cancers associated deaths ${ }^{7}$. The rate of HCV infection prevalence varies between $0.1 \%-12 \%$ and is country dependent ${ }^{5}$. Around 350 million people were living with chronic HBV infection (8-10) and about 160 million people with $\mathrm{HCV}^{4}$ and other declared 170 million people with CHCV infection in 2002 worldwide ${ }^{8}$. In 2009 figure reached 200 million which made $3.3 \%$ of the global population ${ }^{4}$. In Pakistan, around 10 million peoples had HCV infection and the prevalence rates were the highest in the world ${ }^{11}$. Approximately, 7-9\% of peoples are infected HBV in Pakistan at the rate of $3-5 \%{ }^{12}$. China contributes 93 million (46.5) infections alone ${ }^{13}$. In children, globally the HCV infection rate was $54 \%, 28 \%, 21 \%$, and $4 \%$ in low income, lower-middle, upper-middle, and high-income countries respectively ${ }^{14}$. A study on blood donors reported that $4.86 \%$ of donors were having to circulate HBV-DNA ${ }^{15}$. An investigation report on the patients suffering from chronic liver disease (CLD), says that 39 (57\%) were having HBV infection and 30 (43\%) were positive for $\mathrm{HCV}^{16}$. A study on Afghan refugees in Balochistan, Pakistan showed that out 903 of studied subjects overall $8.3 \%$ subjects, $12.3 \%$ husbands, $7.0 \%$ wives and $5.6 \%$ of children were positive for HBsAg. Further, they said that there was a trend of HBV infection in babies if parents were infected with $\mathrm{HBV}^{17}$.

In China, a $6 \%$ prevalence of HBsAg was found in the population of 21-49 years' age ${ }^{18}$. The HBsAg prevalence in vaccinated subjects was $1.3 \%$ and was lower than that of non-vaccinated subjects $4.6 \%(p=0.04)$. The prevalence in males was significantly higher with $p=0.02$ and in 2 years cohort of birth with $p=0.01^{19}$. Occult infection of $\mathrm{HBV}$ is also an important concern Globally ${ }^{20}$. First, it may be difficult to find out every component contributing to the prevalence of infection due to refusal behavior of peoples in developing or underdeveloped countries for the purpose of research and viral screening, and may not feel comfortable to follow the vaccination protocol then. Therefore, such a type of study could give us a more precise prevalence of $\mathrm{HBV}$ and $\mathrm{HCV}$ with a greater proportion of the population. Secondly, Medical and paramedical staff have direct contact with the patients in the whole process of Hospital, either is a surgical, medical or diagnostic. The patient either who has a non-declared infection can transmit the infection. Therefore, it is very important to screen every patient admitted to the Hospital. Nevertheless, in the published literature, we found a study on this topic, so we planned to work on it. Our study was to see the HBV infection and HCV infection prevalence in indoor and outdoor patients and make a comparative discussion of previously published results.

\section{MATERIALS AND METHODS Study plan}

A descriptive, cross-sectional observational study, after approval from advance studies and research board committee, conducted at Benazir Bhutto Shaheed Hospital (BBH) Rawalpindi. In this study, we enrolled and sampled 2003 patients without the restriction of age, sex, and referring department.

\section{Inclusion criteria}

We included the patients either admitted to the hospital or attended the hospital for a checkup in the outdoor department (OPD). Only those patients were sampled, whom their concerned doctor either physician or surgeon advised for viral serology. We then considered for this study in both cases (indoor and OPD).

\section{Sampling and laboratory methods}

After filling enrolment Performa and verbal consent, we withdrew three $\mathrm{ml}$ samples, centrifuged, and separated serum. The serum 
samples were stored at $-30{ }^{\circ} \mathrm{C}$ as aliquots in a freezer. We used the serum for the detection of $\mathrm{HBsAg}$ for HBV infection and anti-HCV antibodies for HCV infection. We used Enzyme-linked immunosorbent assay by using the sandwich technique (sandwich-ELISA) to diagnose HBV and $\mathrm{HCV}$ infections.

\section{Statistical analysis}

We entered the results into a statistical package for social sciences 16 and Microsoft office excel. We applied descriptive statistics as under; for age, we applied a measure of central tendencies (MCT) with Standard deviation (SD) and frequencies in different groups and made a comparison between the ages of different groups by "independent sample t-test." For the rest of the parameters, we calculated frequencies. We received a very little number of samples from some of the departments. In such a case we interpreted the results as follows "if the number of samples from a department or in a group were less than 30 and/or no sample from a department was positive for HBsAg or Anti HCV" we declared the Negativity as $>99.99 \%$ and positivity $<0.01 \%$. We classified the sampled subjects into six groups based on age with equal age intervals. We also used the same in age-based these groups while writing/drafting the results.

\section{RESULTS AND DISCUSSION}

Total enrolled in 2003 patients underwent the process. Some patients were not confirming their ages, so we did not include their ages in statistics. In this way, data of 1542 patients in case of age was available, so for age-related statistics, we included only 1542 patients. After entering data into SPSS and MS office Excel sheet, we measured the frequencies and applied t-test for comparison. Ages of different groups are variable, and differences are significant as well and shown below in Table 1.

The total samples submitted by different departments were 2003. After measuring, the frequencies based on age, we measured the frequencies in the department wise received samples. We have shown the results below for 1609 samples of OPD and 394 samples of indoor patients in Figure 1. Then prepared a summary of the gender wise distribution of participants of the study and summary of their results has shown in Figure 2 shows different patterns. After analyzing gender-based frequencies of results, we grouped data into department wise prevalence of diseases and shown in Table 2. We classified ages of patients into six equal groups from $0-90$ years. We determined the frequencies of different age groups. Table 3 presents the rates of prevalence in different age groups. The prevalence in the case of $\mathrm{HBsAg}$, up to 75 years of age, is increasing with age and $4.55 \%$ was highest observed in the age group 60-75 years and the lowest in the age group under 15 years and above 75 years (Table 3 )

The main findings of the total 2003 sample collected including 762 males and 1241 females in this study are as follows.

The overall prevalence of HBV and HCV in the studied population was $2.6 \%$ and $10.98 \%$ respectively.

Table 1. Comparison of age between different groups.

\begin{tabular}{|c|c|c|c|c|c|c|c|}
\hline & Age & $\mathrm{N}$ & Mean & Mode & $\begin{array}{l}\text { Median } \\
\text { Deviation }\end{array}$ & $\begin{array}{l}\text { Standard } \\
\text { (2-tailed) }\end{array}$ & t-test Sig. \\
\hline & & 1542 & 33.21 & 24 & 32 & 12.002 & ----- \\
\hline \multirow[t]{2}{*}{ Sex } & Male & 600 & 35.03 & 24 & 34 & 12.62 & $<0.001^{*}$ \\
\hline & Female & 942 & 31.89 & 24 & 30 & 12.76 & \\
\hline \multirow[t]{2}{*}{ HBsAg } & Negative & 1497 & 33.12 & 24 & 31 & 11.99 & 0.003 \\
\hline & Positive & 45 & 36.82 & 45 & 36 & 12.553 & \\
\hline \multirow[t]{2}{*}{ Anti-HCV } & Negative & 1381 & 32.71 & 24 & 30 & 11.660 & $<0.001^{*}$ \\
\hline & Positive & 161 & 37.57 & 35 & 35 & 12.643 & \\
\hline
\end{tabular}

*Significant value less than 0.001 . When differences were significant and the $p$-value was lesser than 0.0001 , we expressed the $p$ as less than 0.001 Abbreviation: $\mathrm{N}$ : number of patients, HBsAg: Hepatitis B virus surface antigen; Anti-HCV: Anti HCV antibody. 


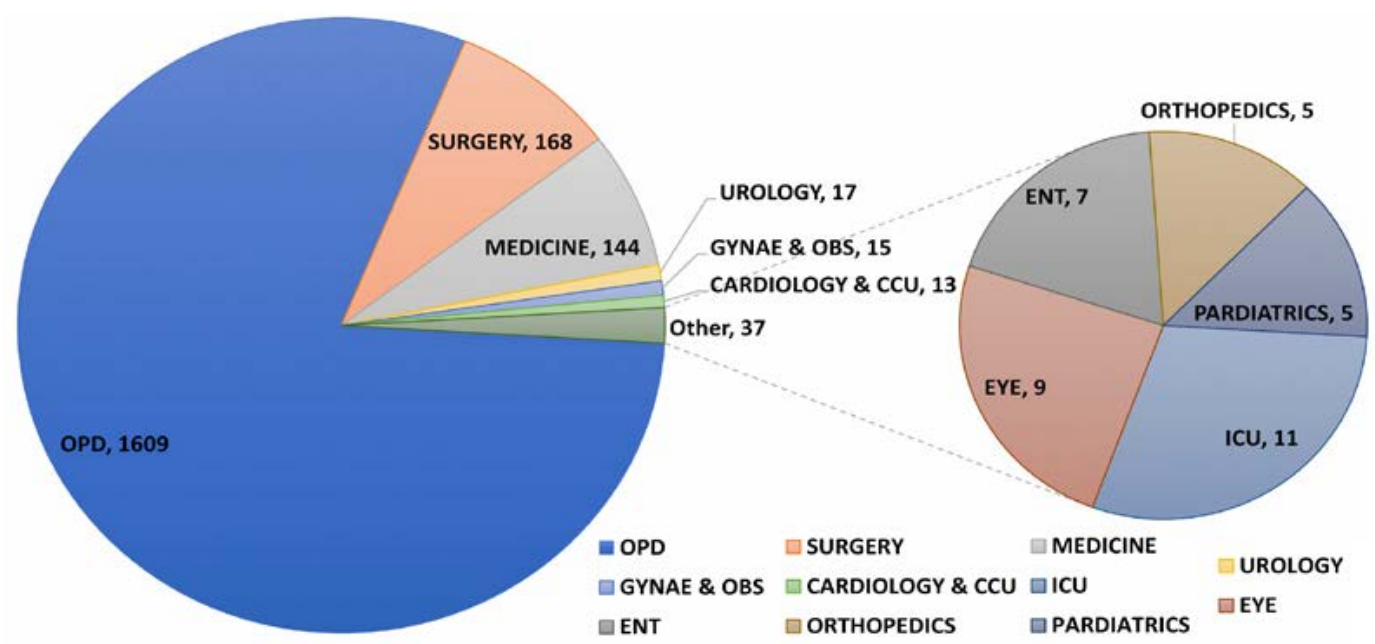

Fig. 1. The frequencies of samples received from different departments and tested for HBsAg and Anti-HCV.

Gynae \& OBS; Gynaecology and Obstetrics, CCU; Coronary Care Unit, ICU; Intensive Care Unit, ENT; Ear, Throat and Nose, OPD; outdoor patients department.

The Prevalence of HBsAg in OPD and indoor patients was $2.30 \%$ and $3.81 \%$ with a greatest in ICU and of HCV was $9.82 \%$ and $15.74 \%$ with the greatest in Med, respectively.

In $\mathrm{HBsAg}$ positive cases, males were predominant being $60.78 \%$ than that of females $39.22 \%$.

In total $01.55 \%$, males and $00.95 \%$ females Positive for $\mathrm{HBsAg}$ and $05.60 \%$ males and 04.40\% were females Positive for HCV.

$\mathrm{BBH}$ is a tertiary care teaching hospital affiliated with Rawalpindi Medical University (formerly known as Rawalpindi Medical College) situated in Rawalpindi; a city adjacent to the federal capital of Pakistan. BBH provides tertiary healthcare facilities to many patients on a daily basis parallel in emergency and OPD. Therefore, the results of this study may be representatives of a larger proportion of the population of the adjacent area. We observed that the prevalence of $\mathrm{HCV}$ to be $10.98 \%$ was too much alarming situation and it is more than twice of previously reported $\mathrm{HCV}$ prevalence that is $4.9 \%^{11}$. The prevalence of HBV $2.6 \%$ is almost in the range of previously reported prevalence range $2.6 \%-8.06 \%$ in all over Pakistan and less than the previously reported prevalence in Rawalpindi $3 \%$ and Islamabad $4 \%{ }^{12}$. These results suggest that no reduction in the prevalence of infection has been found.
In this study, for available participants' age data is suggestive that the most participants are of young age, female participants in this study are even younger than the males, and differences of age based on gender are significant. For HBV infection, for all participant, all the MCTs were greater in the case of HBV infected patients as compared with HBV negative patients. For HCV infection, although the differences are significant, Mean and SD are greater showing the broader range of age for HCV infected patients than that of HBV. The differences are more significant with $P<0.001$ in $\mathrm{HCV}$ as compare to the significance $\mathrm{P}=0.003$ of $\mathrm{HBV}$. These findings are suggestive that the younger have fewer prevalence rates of HBV infection. A report published in 2016 conducted in Nepal at a tertiary care-based health facility, Pokharel et al. ${ }^{21}$ investigated that overall pervasiveness of $2.1 \%$ for $\mathrm{HBsAg}$, and $0.33 \%$ for HCV. Positivity rates for both types of infections found to be higher in male patients although no significant relationship observed. The positivity rates of Hepatitis $B$ and $C$ infection were greater among the age of $46-55$ years and $36-45$ years respectively. It represented any non-significant correlations between the age group and infection $\mathrm{P}>0.05^{21}$. Another study at a tertiary care level investigated the prevalence of $\mathrm{HBsAg}$ to be $2.80 \%$ and the infection rate was higher in males (3.57\%) 
than females (1.98\%). Participant of study within the age range from 31 to 45 year showed the highest prevalence of $5.38 \%$ for $\mathrm{HBsAg}$. Sandhu and Dahiya ${ }^{22}$ at a tertiary care hospital investigated that $4.62 \%$ of people were having HCV infection and contribution from males was $4.96 \%$ and was greater than that of females $4.14 \%$. Seropositivity of $41.13 \%$ the maximum in the $40-59$ years and was followed by $35.46 \%$ in the age range from $20-$ 39 years and $16.31 \%$ in the age from $60-79$ years in males. While in females the highest prevalence was $40 \%$ in the age from 20-39 years followed by of $40-59$ years and the least prevalence was observed $22.35 \%$ in $60-79 y e a r s$ of age ${ }^{22}$. In our study, we have observed among $51 \mathrm{HBsAg}$ Positive samples, there were 31 males and 20 females with significant difference $P<0.001$ and among 220 antiHCV Positive samples, 112 were males and 108 females with nonsignificant correlation $\mathrm{P}<0.001$ with predominant males in both infections. While findings are somehow different as in, point 2 in principal findings under discussion and in the result section as well.
In OPD visiting patients' antibodies against HCV were detected in Ninety-one patient from general surgery, followed by sixty patients from general medicine and twenty-five patients from otorhinology. For indoor, the highest number of cases were Eight from general medicine, then seven from general surgery and two from orthopedic ${ }^{22}$. A study published in 2001 reported $4.06 \%$ prevalence of $\mathrm{HCV}$ in patients of orthopedic and traumatology ward and for HBV infection and $1.09 \%$ of patient had anti-HBV antibodies ${ }^{23}$. A study conducted in Crete that included hospitalized patients reported the rates of viral Hepatitis $B$ and $C$ infections in three prefectures was $2.66 \%$ and $4.75 \%$ accordingly ${ }^{24}$. A study on renal transplant patients conducted in Korea for the investigation of occult hepatitis, reports that the prevalence of viral Hepatitis B infection was $22.8 \%$ that is higher than the general population. Viral Hepatitis $C$ infection was $3.4 \%(13 / 377)^{25}$. A cohort study for 15 years reported the prevalence of HBV $2 \%$ in HCV positive patients ${ }^{26}$.

Table 2. Department wise Observed positivities of HBsAg and anti HCV.

\begin{tabular}{lcccc}
\hline \multirow{2}{*}{$\begin{array}{l}\text { Parameter } \\
\text { Patients }\end{array}$ department } & \multicolumn{3}{c}{ HBsAg } & \multicolumn{2}{c}{ Anti-HCV } \\
\cline { 2 - 5 } & & & & \\
\hline Surg & $161(95.8)$ & $07(4.2)$ & $148(88.10)$ & $20(11.90)$ \\
Med & $137(95.8)$ & $07(4.2)$ & $111(77.10)$ & $33(22.90)$ \\
Orth & $05(>99.999)$ & $00(<0.001)$ & $04(80.00)$ & $01(20.00)$ \\
Uro & $17(>99.999)$ & $00(<0.001)$ & $15(88.20)$ & $02(11.80)$ \\
GOB & $15(>99.999)$ & $00(<0.001)$ & $14(93.30)$ & $01(06.70)$ \\
PEAD & $05(>99.999)$ & $00(<0.001)$ & $05(>99.999)$ & $00(<0.001)$ \\
CCCU & $13(>99.999)$ & $00(<0.001)$ & $12(92.30)$ & $01(07.70)$ \\
ICU & $10(90.00)$ & $00(10.00)$ & $10(90.90)$ & $01(09.10)$ \\
ENT & $07(>99.999)$ & $00(<0.001)$ & $06(85.70)$ & $01(14.30)$ \\
Eye & $09(>99.999)$ & $00(<0.001)$ & $07(77.80)$ & $02(22.20)$ \\
TSID & $379(96.19)$ & $15(3.81)$ & $332(84.26)$ & $62(15.74)$ \\
OPD & $1572(97.7)$ & $37(2.3)$ & $1451(90.18)$ & $158(09.82)$ \\
Total & $1951(97.4)$ & $52(2.6)$ & $1783(89.02)$ & $220(10.98)$
\end{tabular}

Abbreviations: Surg; Surgery, Med; Medicine, Orth; Orthopedic, Uro; Urology, GOB; Gynaecology and Obstetrics, PAED; Pediatrics, CCCU; Cardiology and Coronary Care Unit, ICU; Intensive Care Unit, ENT; Ear, Throat and Nose, TSID; Total samples from indoor, OPD; outdoor patients department. When no positive case was seen in we reported prevalence less than $0.001 \%$ in that specific case. 
Table 3. Observed Frequencies of patients in different age groups.

\begin{tabular}{lllll}
\hline \multirow{2}{*}{$\begin{array}{l}\text { Age Group } \\
\text { (years) }\end{array}$} & \multicolumn{2}{c}{ HBsAg } & \multicolumn{2}{c}{ Anti HCV } \\
\cline { 2 - 5 } & Negative (\%) & Positive (\%) & Negative (\%) & Positive (\%) \\
\hline $00-15$ & $18(>99.99)$ & $00(<0.01)$ & $16(88.89)$ & $2(11.11)$ \\
$16-30$ & $714(97.94)$ & $15(2.06)$ & $682(93.56)$ & $47(6.44)$ \\
$31-45$ & $572(96.46)$ & $21(3.54)$ & $518(87.35)$ & $75(12.65)$ \\
$46-60$ & $146(96.05)$ & $6(3.95)$ & $123(80.93)$ & $29(19.07)$ \\
$61-75$ & $42(95.45)$ & $2(4.55)$ & $37(84.09)$ & $7(15.91)$ \\
$76-90$ & $7(>99.99)$ & $0(<0.01)$ & $6(83.71)$ & $1(14.29)$ \\
Total & $1499(97.15)$ & $44(2.85)$ & $1382(89.57)$ & $161(10.43)$ \\
\hline
\end{tabular}

$\mathrm{N}$ : number of patients, HBsAg: Hepatitis B virus surface antigen; Anti-HCV: Anti HCV antibody.

We observed the increasing prevalence of HBV infection with an increase of age up to the fifth group (61-75 years), the fifth group has the highest prevalence $4.55 \%$ followed by fourth group $3.95 \%$, the third group $3.54 \%$ and the second group $2.06 \%$. In the first group age $0-15$ years and the sixth group age $76-90$ years, no positive case detected. For the HCV infection highest prevalence was in fourth group $19.07 \%$, followed by $15.91 \%$ in the fifth group, $14.29 \%$ in the sixth group, $12.65 \%$ in the third group, $11.11 \%$ in the first group and the second group showed the lowest prevalence rate $6.44 \%$. No published data found representing the prevalence of HBV in patients admitted to hospital or attending OPD for a checkup. So here, we give some comparison with published statistics of HBV prevalence published in a specific group of patients. A study on volunteer blood donors 16-22 years of age, reported that HBV was prevalent in $1.76 \%$ tested subjects and HCV was prevalent in

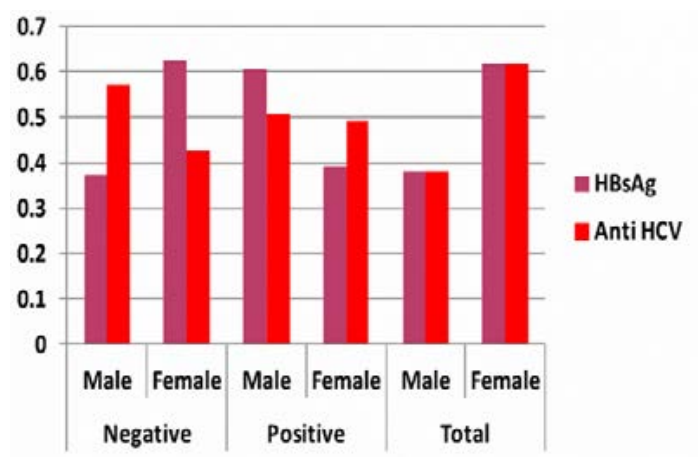

Fig. 2. The gender-wise proportion of submitted samples and the summary of HBsAg and Anti-HCV infections
$2.15 \%$ (8). In between $18-52$ years the prevalence of HBsAg was $3.0 \%{ }^{27}$. A study in South Africa on HBsAg seronegative HIV patients investigated that HBV genome discovered from the serum of $\% .4 \%$ seronegative patients ${ }^{28}$. The highest prevalence rates observed were $5.4 \%$ in the age from $21-40$ year of male and $3.09 \%$ in the females of 41 60 years. For HCV infection the highest rate of infection was7.19\% in males from $41-60$ years of age and $61-90$ years for females $(7.16 \%)^{24}$.

\section{CONCLUSION}

After this study, we concluded that the rate of the pervasiveness of $B$ and $C$ hepatitis virus is high in public sector hospital which representative of many population and is variable from department to department. Therefore, hospitalized patients may be a factor taking part in the spread of HBV and HCV infection especially to the hospital staff and admitted patients. Although Hospital staff is vaccinated against HBV infection still there is a risk of infection transmission. The hospital staff is in close exposure to patients in surgical and clinical procedures, so is a high risk of infection transmission. Because everyone comes to Hospital in the early years of age, therefore we would like to suggest screening of hospitalized and hospital visiting patients in endemic areas would be a good evolution to know the more facts, risk factors, and infection control as well. Vaccination of seronegative individuals and counseling of seropositive patients may be promising. Physicians and Clinician can play an effective role especially in areas with low literacy rate. 


\section{ACKNOWLEDGMENTS}

We thankfully acknowledge the Institutional resources of BBH Rawalpindi, allowed under letter No.6/BBH. Dated 16.06.2016.

\section{CONFLICT OF INTEREST}

The authors declare that there is no conflict of interest.

\section{AUTHORS' CONTRIBUTION}

All listed author(s) have made a substantial, direct and intellectual contribution to the work, and approved it for publication.

\section{FUNDING}

None.

\section{ETHICS STATEMENT}

This study was conducted after ethical approval from ethical committee of BBH Rawalpindi under letter number 6/BBH dated 16.06.2016.

\section{DATA AVAILABILITY}

Not applicable.

\section{REFERENCES}

1. Block TM, Alter HJ, London WT, Bray M. A historical perspective on the discovery and elucidation of the hepatitis B virus. Antiviral Research. 2016;131:109-23. https://doi.org/10.1016/j.antiviral.2016.04.012

2. Alter H. Discovery of non-A, non-B hepatitis and identification of its etiology. Am J Med. 1999;107(6):1620. https://doi.org/10.1016/S0002-9343(99)00375-7

3. Waheed Y, Shafi T, Safi SZ, Qadri I. Hepatitis C virus in Pakistan: a systematic review of prevalence, genotypes and risk factors. World I Gastroenterol: WJG. 2009;15(45):5647. https://doi.org/10.3748/ wjg.15.5647

4. Almani MIK, Kazmi A, Haider I, et al. Correlation of Duration of Hepatitis C Infection with Triglycerides and Total Cholesterol. Journal of Islamabad Medical \& Dental College. 2016;5(4):168-71.

5. Houghton $M$. The long and winding road leading to the identification of the hepatitis C virus. J Hepatol. 2009;51(5):939-48. https://doi.org/10.1016/j. jhep.2009.08.004

6. Kazmi A, Tariq KM, Sattar A, Hashim R, Almani MI. Determination of insulin resistance and beta cell function in healthy obese and non-obese individuals. PAFMJ. 2013;63(3):295-99.

7. Yang $Y$, Zhou J, Yang $Y$, Chen Z, Zheng $X$. Systematic review and meta-analysis: dairy consumption and hepatocellular carcinoma risk. Journal of Public Health. 2017;25(6):591-9. https://doi.org/10.1007/s10389017-0806-3
8. Ilyas MU, Iftikhar MU, Rasheed US. Prevalence of hepatitis $B$ and hepatitis $C$ in populations of college students in Gujranwala. Biol Pak. 2011;57(1\&2):89-95.

9. Ding X, Lei Q, Li T, Li L, Qin B. Hepatitis B core antigen can regulate NLRP3 inflammasome pathway in HepG2 cells. J Med Virol. 2019;91(8):1528-36. https://doi. org/10.1002/jmv.25490

10. Feng S, Ji G, Ma J, Wang Z, Zhao Y, Tao C. Long noncoding RNA GAS5 does not regulate HBV replication. J Med Virol. 2019;91(11):1949-59. https://doi.org/10.1002/ jmv.25547

11. Naseer F, Mukhtar A, Ahmed A, Raza A. Hepatitis C diagnostic management gap in Pakistan-Clinicians' knowledge impacting public health. Journal of Public Health. 20161;24(4):299-305. https://doi. org/10.1007/s10389-016-0725-8

12. Ali M, Idrees M, Ali L, Hussain A, Rehman IU, Saleem S, Afzal S, Butt S. Hepatitis B virus in Pakistan: a systematic review of prevalence, risk factors, awareness status and genotypes. Virology Journal. 2011;8(1):102. https://doi.org/10.1186/1743-422X-8-102

13. Wang $X$, Chen $Q$, Li $H$, et al. Asymptomatic hepatitis $B$ carriers who were vaccinated at birth. J Med Virol. 2019;91(8):1489-98. https://doi.org/10.1002/ jmv.25461

14. Gower E, Estes C, Blach S, Razavi-Shearer K, Razavi H. Global epidemiology and genotype distribution of the hepatitis C virus infection. J Hepatol. 2014;61(1):S4557. https://doi.org/10.1016/j.jhep.2014.07.027

15. Sofian M, Aghakhani A, Izadi N, et al. Lack of occult hepatitis $B$ virus infection among blood donors with isolated hepatitis $B$ core antibody living in an HBV low prevalence region of Iran. Int J Infect Dis. 2010;14(4):e308-10. https://doi.org/10.1016/j. ijid.2009.05.011

16. Saravanan S, Velu V, Kumarasamy N, Shankar EM, Nandakumar S, Murugavel KG, Balakrishnan P, Solomon SS, Solomon S, Thyagarajan SP. The prevalence of hepatitis $B$ virus and hepatitis $C$ virus infection among patients with chronic liver disease in South India. Int J Infect Dis. 2008;12(5):513-8. https:// doi.org/10.1016/j.ijid.2008.02.006

17. Quddus A, Luby SP, Jamal Z, Jafar T. Prevalence of hepatitis $B$ among Afghan refugees living in Balochistan, Pakistan. Int J Infect Dis. 2006;10(3):242-7. https://doi.org/10.1016/j.ijid.2005.04.007

18. Liu J, Zhang $S$, Wang $Q$, et al. Seroepidemiology of hepatitis $B$ virus infection in 2 million men aged 21-49 years in rural China: a population-based, cross-sectional study. The Lancet Infectious Diseases. 2016;16(1):80-6. https://doi.org/10.1016/S14733099(15)00218-2

19. Odusanya OO, Alufohai FE, Meurice FP, Wellens R, Weil J, Ahonkhai VI. Prevalence of hepatitis B surface antigen in vaccinated children and controls in rural Nigeria. Int J Infect Dis. 2005;9(3):139-43. https://doi. org/10.1016/j.ijid.2004.06.009

20. Javanmard D, Namaei $M H$, Farahmand $M$, Ziaee A, Amini E, Ziaee M. Molecular and serological characterization of occult hepatitis $B$ virus infection among patients with hemophilia. J Med Virol. 
2019;91(8):1519-27.

21. Pokharel N. Pattern of hepatitis B and C infections among patients attending a tertiary care hospital in Kathmandu, Nepal. Journal of Institute of Medicine. 2017;40(2).

22. Sandhu R, Dahiya S. Prevalence of Anti-Hepatitis C Virus Antibodies among Inpatients and Outdoor Attendees of a Tertiary Care Institute. Advanced Biomedical Bulletin. 2015;3(1):08-14.

23. Santos M, Danguilan R, Que E, Balmaceda R, Padilla B. Prevalence of hepatitis $B$ and hepatitis $C$ in haemodialysis patients. Nephrology. 1998;4(1):101-4. https://doi.org/10.1046/j.1440-1797.1998.d01-6.x

24. Koulentaki M, Ergazaki M, Moschandrea J, et al. Prevalence of hepatitis $B$ and $C$ markers in high-risk hospitalised patients in Crete: a five-year observational study. BMC Public Health. 2001;1(1):17. https://doi. org/10.1186/1471-2458-1-17

25. Bae E, Park $\mathrm{CH}, \mathrm{Ki} C \mathrm{CS}$, et al. Prevalence and clinical significance of occult hepatitis $B$ virus infection among renal transplant recipients in Korea. Scand J Infect Dis. 2012;44(10):788-92. https://doi.org/10.3109/003655 48.2012.680488

26. Bolther M, Dalgaard LS, Kristensen LH, Tarp BD, Jensen-Fangel $S$. Testing for hepatitis $B$ virus and HIV in patients with chronic hepatitis C: screening performance and outcome. Scand J Infect Dis. 2014;46(10):686-92. https://doi.org/10.3109/00365 548.2014.929734

27. El Beltagy KE, Al Balawi IA, Almuneef M, Memish ZA. Prevalence of hepatitis $B$ virus markers among blood donors in a tertiary hospital in Tabuk, northwestern Saudi Arabia. Int J Infect Dis. 2008;12(5):495-9. https:// doi.org/10.1016/j.ijid.2008.01.010

28. Firnhaber C, Chen CY, Evans D, et al. Prevalence of hepatitis $B$ virus (HBV) co-infection in HBV serologically-negative South African HIV patients and retrospective evaluation of the clinical course of monoand co-infection. Int J Infect Dis. 2012;16(4):e268-72. https://doi.org/10.1016/j.ijid.2011.12.007 